Supplement of Adv. Sci. Res., 18, 115-126, 2021

https://doi.org/10.5194/asr-18-115-2021-supplement

(C) Author(s) 2021. CC BY 4.0 License.

(c) (i)
Advances in

Science \& Research

Open Access Proceedings

Supplement of

\title{
Evaluation of wind speed estimates in reanalyses for wind energy applications
}

\section{Sebastian Brune et al.}

Correspondence to: Sebastian Brune (sebastian.brune@dwd.de)

The copyright of individual parts of the supplement might differ from the article licence. 
hilly

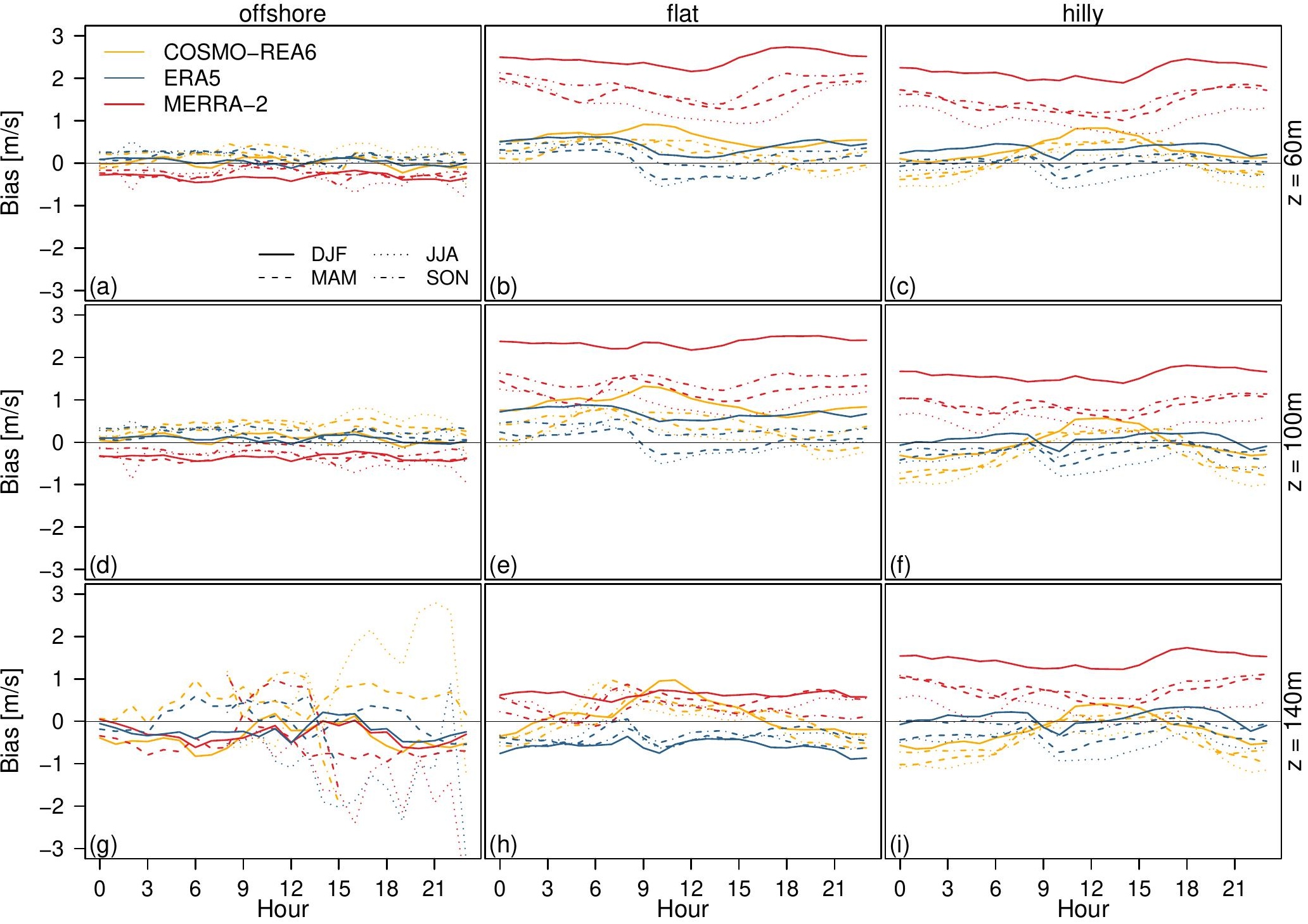

